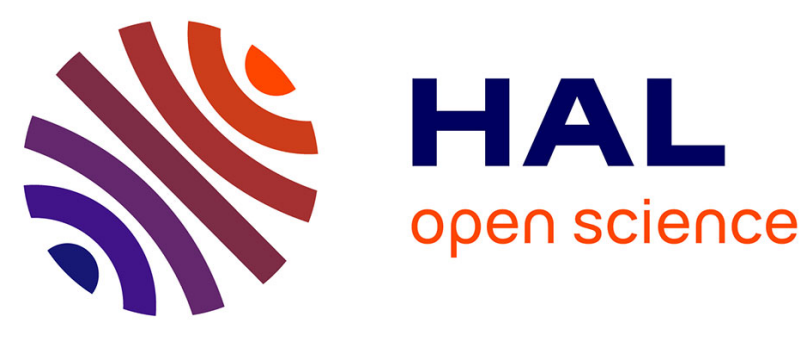

\title{
Angiovision: Aortic stent-graft placement by augmented angionavigation.
}

\author{
Pascal Haigron, Aurélien Dumenil, Adrien Kaladji, Michel Rochette, \\ Benyebka Bou Said, Simon Esneault, Hélène Walter-Le Berre, Ghizlane \\ Mouktadiri, Miguel Castro, Pierre Louat, et al.
}

\section{To cite this version:}

Pascal Haigron, Aurélien Dumenil, Adrien Kaladji, Michel Rochette, Benyebka Bou Said, et al.. Angiovision: Aortic stent-graft placement by augmented angionavigation.. Innovation and Research in BioMedical engineering, 2013, 34 (2), pp.167-175. 10.1016/j.irbm.2013.01.016 . hal-00879682

\section{HAL Id: hal-00879682 https://hal.science/hal-00879682}

Submitted on 14 Nov 2013

HAL is a multi-disciplinary open access archive for the deposit and dissemination of scientific research documents, whether they are published or not. The documents may come from teaching and research institutions in France or abroad, or from public or private research centers.
L'archive ouverte pluridisciplinaire HAL, est destinée au dépôt et à la diffusion de documents scientifiques de niveau recherche, publiés ou non, émanant des établissements d'enseignement et de recherche français ou étrangers, des laboratoires publics ou privés. 


\section{ANGIOVISION: Aortic stent-graft placement by augmented angionavigation}

\section{ANGIOVISION : Pose d'endoprothèse aortique par angionavigation augmentée}

P. Haigron ${ }^{\mathrm{a}, \mathrm{b}}$, A. Duménil ${ }^{\mathrm{a}, \mathrm{b}, \mathrm{c}}$, A. Kaladji ${ }^{\mathrm{a}, \mathrm{b}, \mathrm{d}}$, M. Rochette $^{\mathrm{e}}$, B. Bou Said ${ }^{\mathrm{f}}$, S. Esneault ${ }^{\mathrm{c}}$, H. Walter-Le Berre, , G. Mouktadiri ${ }^{\mathrm{f}}$, M. Castro ${ }^{\mathrm{a}, \mathrm{b}, \mathrm{d}}$, P. Louat ${ }^{\mathrm{e}}$, D. Roche ${ }^{\mathrm{e}}$, C. Göksu ${ }^{\mathrm{c}}$, J. Marzelle ${ }^{\mathrm{g}}$, A. Cardon ${ }^{\mathrm{d}}$, J.P. Becquemin ${ }^{\mathrm{g}}$, A. Lucas ${ }^{\mathrm{a}, \mathrm{b}, \mathrm{d}}$

${ }^{a}$ INSERM, U1099, Campus de Beaulieu, Rennes, F-35000, France ${ }^{b}$ Université de Rennes 1, LTSI, Campus de Beaulieu, Rennes, F-35000, France ${ }^{c}$ Therenva, CCP-CHU Pontchaillou, Rennes, F-35000

${ }^{d}$ CIC-IT 804, CCP-CHU Pontchaillou, Rennes, F-35000, France

${ }^{e}$ ANSYS France, Avenue Albert Einstein, Villeurbanne, F-69100, France

${ }^{f}$ Université de Lyon, CNRS INSA-Lyon, LaMCoS, UMR5259, Avenue Albert Einstein, Villeurbanne, F-69100, France

${ }^{g}$ Vascular Department, University Hospital Henri Mondor, Av. du Maréchal de Lattre de Tassigny, Créteil, F-94010, France

*Corresponding author.

Phone: +33223236919

E-mail address: pascal.haigron@univ-rennes1.fr (P. Haigron)

LTSI INSERM U1099, Université de Rennes 1, Campus de Beaulieu, 35042, Rennes 


\title{
ANGIOVISION: Aortic stent-graft placement by augmented angionavigation
}

\author{
ANGIOVISION : Pose d'endoprothèse aortique par \\ angionavigation augmentée
}

\begin{abstract}
The endovascular treatment of abdominal aortic aneurism (EVAR - EndoVascular Aneurism Repair) has become an alternative therapy to conventional open surgery. The objective of ANGIOVISION project was to contribute to the improvement of EVAR procedures in terms of accuracy and customization of the interventional strategy. Our approach was mainly based on the use of patient specific data, computer aided endovascular navigation and numerical simulation. We proposed a new FEM based patient specific simulation solution to estimate the deformations caused by the introduction of stiff endovascular devices. We developed and implemented an original endovascular navigation system to augment the intra-operative fluoroscopy with the visualization of deformed pre-operative aorto-iliac structure, and related information concerning vessel wall (calcifications), as well as stentgraft virtual deployment. The proposed solution, that requires only lightweight computer equipment, can be used in a standard operating room in order to optimize device placement (from a single angle of incidence). Evaluation is currently under way.
\end{abstract}

\section{Résumé}

Le traitement endovasculaire de l'anévrisme de l'aorte abdominale (EVAR - EndoVascular Aneurism Repair) constitue une alternative à la chirurgie ouverte. Le projet ANGIOVISION avait pour objectif de contribuer à l'amélioration des procédures EVAR en termes de précision et de personnalisation de la stratégie opératoire. Notre approche était principalement fondée sur le recours aux données spécifiques au patient, à la navigation endovasculaire assistée par ordinateur, et à la simulation numérique. Nous avons proposé une nouvelle solution de simulation par éléments finis, spécifique patient, afin d'estimer les déformations engendrées par les outils endovasculaires. Nous avons développé et mis en oeuvre un système de navigation endovasculaire permettant d'augmenter l'imagerie fluoroscopique per-opératoire avec la représentation de la structure aorto-iliaque préopératoire déformée, incluant les informations relatives à la qualité pariétale, ainsi que le pré-déploiement virtuel de l'endoprothèse. La solution proposée, qui n'implique que des moyens matériels (informatiques) légers, peut être utilisée dans un bloc opératoire standard afin d'optimiser le placement des dispositifs endovasculaires (à partir d'une seule incidence d'acquisition). L'évaluation du système est actuellement en cours. 


\section{INTRODUCTION}

Abdominal aortic aneurysm (AAA) is the most common aortic aneurysm. The endovascular treatment of AAA (EVAR - EndoVascular Aneurism Repair) has become an alternative therapy to conventional open surgery [1-2]. It consists in the deployment of one or several stent-grafts, through intravascular ways, at their anchorage site, in order to re-channel the blood flow excluding thrombus. This procedure has a high success rate in the short term, has the advantage of reducing blood loss, intraoperative morbidity and duration of hospitalization. Although some issues remain, the indication of EVAR is constantly increasing, compared to open surgery.

However, EVAR shows inherent limitations that make difficult its implementation in a number of cases [3-4]. This minimally invasive procedure still needs to be made more reliable and secure. Some of these limitations are related to the realization of the endovascular gestures in complex anatomical configurations, the information feedback provided by the intraoperative 2D imaging (fluoroscopy), the durability of the treatment (need for secondary procedures in the medium and long term).

While the main actors of the field agree to recognize the difficulties encountered during stent-graft placement, computer aided solutions are largely under-exploited (or even nonexistent) in the current practice of endovascular interventions, including EVAR procedures. Most of vascular surgeons still work with a standard intra-operative 2D fluoroscopy-like imaging. The best imaging to guide the intervention would be the superimposition of the preoperative CT volume onto the intra-operative imaging environment thanks to a registration 
process [5]. Nevertheless, introduction of a stiff guidewire or an aortic stent naturally makes arteries, and in particular the iliac arteries, straighten and deform. Pre-operative planning based on the pre-operative CT-scan may thus turn out to not match the intra-operative morphology. The prediction of intra-operative deformations has to be taken into account in the intraoperative navigation / fusion system. Currently there is no satisfactory solution available in practice.

Computer-aided surgery makes use of a variety of technologies and information sources. One of the challenges over the last years has been to apply these methods to tissues that deform, as do vessels when flexible and relatively stiff objects are introduced into them (stiff guidewire, aortic prosthesis, etc.). Patient specific simulation of instruments / tissues interactions is a complex issue. It is even more complex that intra-operative observations showing the endovascular devices interacting with tissues are available but paradoxically not exploited. Moreover, it is surprising that the visual feedback to the practitioner during the intervention is limited to 2D fluoroscopic imaging.

In this context, ANGIOVISION project was aimed at improving EVAR procedures in terms of accuracy and customization of the interventional strategy. To tackle problems of iterative procedures, risks of failure or conversion, it was a question of developing an operational solution for the tracking and control of stentgraft placement, incorporating a realistic modeling of tools / tissues interactions. The approach was mainly based on the use of patient specific data, computer aided endovascular navigation and numerical simulation. The main objective of the project was to use complementary patient-specific information available at different stages of observation (pre-, intra-operative), in order to import in the operating room the decision making support and display it to the practitioner during the procedure, through an augmented reality endovascular navigation system. 


\section{MATERIALS AND METHODS}

The different methodological steps involved in the solution proposed for computer aided endovascular navigation are presented in the following. They include: pre-operative CT data analysis and description, FEM based simulation, pre-/intra-operative registration, and Intraoperative fusion and updating.

\section{1 - Preoperative patient data}

For each patient the pre-operative CTA (computed tomography angiography) was analyzed using the Endosize ${ }^{\circledR}$ software [6] (Therenva, Rennes, France). The image analysis process combines contour-based and region-based segmenting algorithms including morphological operations to automatically remove connections between the vasculature of interest (aortoiliac structure) and bone structures (such as spine). The vessel centerlines and contours, as well as the surface description of the vascular lumen were extracted from the CTAs. The vascular structures were described using active contours, and were represented by curves (B-spline type) in planes orthogonal to the centerline of each vessel. In addition, a complete sizing was performed and the arterial wall quality (healthy wall, calcifications) was determined, according to the standards of the international society for vascular surgery [7]. The grade 0 corresponded to a healthy wall and the (maximum) grade 3 corresponded to circular calcifications of the whole artery.

\section{2 - Implicit FEM simulation}

Rather than the development of a detailed biomechanical model (as studied in the next section), this approach was deliberately oriented towards an approximate solution consistent with the clinical workflow [8]. The simulation of vessel deformations was mainly based on the 
construction and tuning of a biomechanical model, simulation of tool-tissue interactions via implicit finite-element analysis, and projection of deformed model on intraoperative imaging.

Reconstruction of the vascular geometry was achieved using the ANSYS DesignModeler software (ANSYS, Inc., Canonsburg, PA). The contours were imported from Endosize®, and by using a surface interpolation tool, the full aortic surface was recreated (Fig. 2). From this geometric model, a triangular mesh was generated and contained (depending on the patient) between 5000 and 10000 shell elements [9]. The thickness of the artery wall was $1.5 \mathrm{~mm}$ on the aorta [10] and $1 \mathrm{~mm}$ on the iliac arteries. The vascular wall was considered to be homogeneous, isotropic and incompressible, with a Poisson's ratio of 0.45. A linear elastic model was used to describe the deformation properties of the arterial wall. The mechanical properties of the artery wall were determined from the calcification grade, determined from the sizing. Based on the literature [11], [12] the values of Young's Modulus (defining the elasticity) were applied as follows: non or minimally calcified artery (grade 0 or 1): $2 \mathrm{MPa}$; calcified artery (grade 2): $5 \mathrm{MPa}$; highly calcified artery (grade 3): $10 \mathrm{MPa}$.

The boundary conditions are the parameters defining the mechanical stresses or displacements acting on the geometric structure under consideration from external sources. They can take different forms as fixed points (fixed support) or spring stiffness per unit area that only acts in the direction normal to the face of the mesh (elastic support). Anatomical knowledge was considered to choose the location of the boundary conditions [13]. The superior extremity of the abdominal aorta is fixed by the aortic hiatus (strong tendinous close to the spine). The femoral artery is also fixed in the femoral triangle by its collaterals laterally and the inguinal ligament forwards. Between the coeliac aorta and the femoral artery, there is no other strong anatomical structure able to fix the aortoiliac structure. Thus, in this study (Fig. 2), the superior extremity of the abdominal aorta (A) and the guidewire insertion site on the femoral artery (B) were assumed to be fixed. Elastic supports were used to model the 
anatomical relationship between the posterior side of the aorta and the anterior side of the spine (C). Other supports were added between the aortic bifurcation and the internal iliac bifurcation (D).

The tool used in this analysis was a Lunderquist ${ }^{\circledR}$ (Extra Stiff Wire Guide, Cook®) stiff guidewire, which is used by surgeons to facilitate the insertion of aortic stent grafts during EVAR procedures. Among endovascular tools (flexible guidewire, deployment device), it is known for most seriously deforming vascular structure. In the model, the guidewire was represented by a circular beam with a diameter of $0.889 \mathrm{~mm}$. Its mechanical behavior was defined by a linear elastic material model. Its properties were set at standard values for an extra-stiff guidewire (Young's modulus of $200 \mathrm{GPa}$ and Poisson's coefficient of 0.3) [14], $[15]$.

The simulation consisted in displacing the whole guidewire onto the centerline of the aortoiliac structure, using pre-stress to initialize the guidewire/artery interactions (Fig. 3). The pre-stress was then removed and the guidewire/artery contact activated.

\section{3 - Explicit FEM simulation}

The objective was here to study the feasibility of patient-specific simulation based on a more accurate biomechanical model in order to perform a patient specific simulation of toolstissues interactions via explicit finite-element analysis. Gradual insertion of multiple endovascular devices was considered.

Looking at literature it is obvious that there is a lack of data on the mechanical properties of calcified arteries [16]. We have performed mechanical testing of arterial tissues, differentiating some components (calcification, atheromatous lesions, healthy tissues), in order to integrate these mechanical characteristics in the numerical model. Femoral, iliac and aortic samples have been tested. The samples were selected and characterized according to arterial wall 
quality: CT data that contain information on tissue density and nature were translated in terms of mechanical properties. An atomic force microscope (AFM), a tribometer and rheometer were used to characterize the mechanical behavior in compression, shearing and friction of different layers of arteries. A large number of samples (474) were tested in a liquid environment (PBS buffer $\mathrm{pH}$ 7.4) at room temperature. These tests have led to the determination of mechanical properties of different layers as a function of the degree of calcification. Fig. 4 illustrates the mapping of material properties (elastic modulus and friction coefficient) onto the anatomical description (obtained from pre-operative CT images).

When it comes to the endovascular tools, the stiff guidewire enables setting up the path of the delivery catheter system. The guidewire is composed of three main areas: a head that is very flexible ( 3 to $7 \mathrm{~cm}$ in length), an abrupt or progressive transition portion (11 to $15 \mathrm{~cm}$ ), and a rigid part $(162$ to $245 \mathrm{~cm})$. The delivery catheter contains the stent; it has a $0.889 \mathrm{~mm}$ internal diameter that allows its navigation in interaction with the guide. It is also composed of several main areas: the tip with variable diameter, the area containing the stent, the tubular area, and the sheath. It is of variable construction (platinum-iridium, nickel, nitinol, polyester, etc.). Tests were conducted for each region, considering the variation of mechanical properties (Fig. 5). The 3D image correlation was found to be the best tool to follow this variation. The samples were subjected to uniaxial quasi-static tension and were fixed between two jaws. The testing machine was connected to an image acquisition system, with lighting and 3D correlation.

Due to the presence of large deformations an Updated Lagrangian description was chosen for the simulation. The arterial walls were modeled using thin shell theory with Kirchhoff approach. The delivery system was modeled using Timoshenko beam elements. Considering the strong nonlinearity of the problem, the explicit time integration scheme [17], [18] was adopted (method $\beta-2)$. The contact between the tools and biological tissues was managed by 
unilateral penalty conditions, which consist of increasing the functional of total energy by a penalty function [19].

Fig. 6 illustrates guidewires and catheter navigation from the incision area to the neck of the aneurysm for a patient with strong angulations and calcifications.

\section{4 - Pre-/intra-operative registration}

In order to evaluate the results of the simulation, the simulated guidewire was projected onto the intraoperative image of the operated patient, and then compared with the real guidewire. 2D/3D registration was implemented in order to align the preoperative 3D simulation with the $2 \mathrm{D}$ intraoperative images. The $2 \mathrm{D}$ intraoperative centerlines were extracted from a frontal digital substraction angiography (DSA). It was acquired at the beginning of the procedure and included the entire abdominal aorta until the femoral arteries. For this DSA there was no device within the arteries able to deform the aortoiliac structure. After the acquisition of the DSA, the lunderquist was inserted until its final position without displacement of the c-arm. This protocol allowed the registration between the preoperative 3D centerlines extracted from the CTA and the 2D intraoperative centerlines extracted from the undeformed DSA. The rigid transformation between the preoperative 3D coordinate system (CTA) and the intraoperative 2D coordinate system (fluoroscopy) was estimated using a feature-based similarity measure, i.e. the distance to the centerline of the vascular structures computed in the intraoperative image. According to this rigid transformation the simulated guidewire could be superimposed on the 2D fluoroscopy image of the real guidewire. Thus for each patient, the simulation was assessed on the basis of two errors (Fig. 7). The first of these was the error associated with the registration procedure, which was calculated from the mean distance (Euclidean 2D distance) between the projected 3D pre-operative centerlines and those extracted from the $2 \mathrm{D}$ intraoperative image. The second error was that associated with the 
simulation, which was computed by measuring the 2D mean distance between the simulated and real guidewires.

A set of 10 patients was used to adjust the simulations according to the outcomes they produced, thus allowing the model parameters to be tuned. Behavior laws were established between parameter values and patient data to make the model adaptive. In this training group, the location and the value of the elastic supports were adjusted interactively to minimize the simulation error.

\section{5 - Intra-operative fusion and updating}

Despite this parameters tuning, the simulation could not be fully predictive. In order to improve the pre-operative / intra-operative matching accuracy, a correction step, based on intraoperative imaging, was added at the end of the simulation. This additional step consisted in projecting the simulated guidewire onto an intraoperative image, evaluating the $2 \mathrm{D}$ distance between the two guidewires (real and simulated) and restarting the simulation at its end in order to correct the position of the simulated guidewire. A coordinate system was associated with some points of the simulated guidewire in order to perform this adjustment. These coordinate systems took into account some characteristics of the intra-operative imaging system: the first axis was directed to the X-ray source and the second was aligned longitudinally with the guidewire. The displacements necessary to improve the superimposition of the simulated guidewire with the real one were evaluated on the third axis by quantifying the distance between the two guidewires (real and simulated). The simulation was then restarted at its end and the displacements were applied to the guidewire points: one degree of freedom was fixed by the displacement and the others were determined mechanically. 


\section{RESULTS}

\section{1 - Implicit FEM Simulation}

We present here the results of implicit FEM simulation which was integrated in the computer aided navigation system.

Simulations were carried out using the Ansys Mechanical finite-element solver on a Hewlett Packard Z800 workstation (HP Development Company, California, USA) equipped with a 6-core Xeon processor $(3.46 \mathrm{GHz})$. A first manual tuning of the parameters was performed on the training group. Model parameters were adjusted independently for each of the 10 patients, taking into account simulation results projection on the intraoperative images. The mean simulation-related error was $2.1 \pm 0.8 \mathrm{~mm}$. Based on these parameters, two behavior laws were established between parameter values and patient data. Model parameters for each patient were then modified during a second phase in order to check the previously established laws. Mean simulation-related error (including registration error) was $2.3 \pm 0.6 \mathrm{~mm}$.

One patient's intra-operative data was used to match 3D and 2D data on a second incidence. Simulation results could thus be compared with intraoperative imaging not used for the tuning of the model parameters. The simulated guidewire was thus projected on two images with a different angle of incidence (left anterior oblique [LAO] $20^{\circ}+$ caudal $13-15^{\circ} /$ LAO $30^{\circ}+$ caudal $13-15^{\circ}$ ). The simulation-related error for this patient was $3.5 \pm 2.5 \mathrm{~mm}$ for the first incidence and $2.0 \pm 1.3 \mathrm{~mm}$ for the second incidence.

\section{2 - pre- / intra- operative fusion and updating}

The FEM-based matching was applied to a test group of 12 patients using the adaptive model. Mean simulation-related error (including registration error) was $2.9 \pm 0.5 \mathrm{~mm}$. Mean simulation calculation time was of about 300 seconds. For example, time for all the process, 
for one of these patients, was 10 minutes for data analysis and extraction, 10 minutes for preparation of the simulation, 5 minutes for simulation and 2 minutes for registration. Simulation results can thus be used to integrate the deformation of the aorto-iliac structure in 3D/2D fusion (Fig. 8). The matching between the vascular structure and the observed guidewire is largely improved when the deformed model is used.

Fig. 9 illustrates the results of intra-operative updating of the simulation of tool tissue interactions in the aorto-iliac structure. The intra-operative observation of endovascular tool (stiff guidewire) interacting with the tissues was used to update the shape of the aorto-iliac structure. Since there are low deformations between initial simulated structure and simulated structure updated intra-operatively, the updating computation time was relatively low (111 seconds in this case), and compatible with intra-operative implementation. Updating error was given by the distance between updated simulation of the guidewire and the real one observed in the 2D intra-operative image. Mean updating error was of about $0.6 \mathrm{~mm}$.

\section{3 - Augmented angionavigation system}

A demonstrator of the augmented angionavigation system has been developed. It integrates image processing and patient data description, implicit FEM simulation results, pre-/intraoperative registration, intra-operative fusion and updating. In addition, a user interface has been designed and developed. It integrates visualization and geometrical deployment of the stentgraft to augment the real intra-operative image during EndoVascular Aneurism Repair.

The geometrical deployment consisted in displaying the different stentgrafts used during the endovascular procedure into the vascular structure, before the real deployment (Fig. 10).

Each stentgraft was represented by a 3D mesh which was modeled from the dimensions of the real stentgraft. Each mesh could be moved along a vessel centerline and be rotated around it (Fig. 11). After a modification of the stentgraft position, the overlap between it and the 
surrounding stentgrafts was updated and displayed. The geometrical deployment could be displayed in the 3D CTA or projected onto the intra-operative fluoroscopy. It could also be displayed in the deformed vascular structure evaluated by the biomechanical simulation.

The augmented angionavigation system is currently under evaluation in clinical routine conditions (Fig. 12).

\section{DisCUSSION}

A few works have focused on computer aided navigation to assist endovascular repair of complex aortic aneurysms. Intensity based [20][21] and feature based [22][23] 3D/2D rigid registration methods have been considered. Due to intra-operative deformations of vascular structures it is difficult to achieve an accuracy of about one millimeter. More recent works integrated non-rigid registration to take into consideration local deformations, of the renal ostia, observed between 3D CT pre-operative data and intra-operative images. The results reported from use of the image-guided surgery system during 23 procedures showed that the method was within a target accuracy of $3 \mathrm{~mm}$ in $78 \%$ of cases. The deformation of the iliac arteries caused by the introduction of stiff endovascular tools was not taken into account. Otherwise several works attempted to implement Finite Element Methods (FEM) based simulation in the context of endovascular procedures. They were intended to deal with issues related to the understanding and the anticipation of aneurysm rupture risk, of strain, migration and endoleaks at the stent, in their pre-computed implementation [24][25] or to deal with catheterization simulation issues in their interactive / real time implementation [26][27]. With the extension of EVAR to more and more complex cases, especially for patients eligible for fenestrated endograft, one of the remaining technical challenge concerns deformations.

In the ANGIOVISION project we proposed an augmented reality solution for EndoVascular Aneurism Repair. To perform the matching / fusion of preoperative and 
intraoperative data, our approach involves biomechanical simulation of the interactions between anatomical structures and endovascular material as well as 3D preoperative - 2D intraoperative rigid registration. Based on preliminary analysis and description of preoperative CT images (i.e. patient data), vessel deformations were computed during preoperative phase, using a patient specific finite element model. The process was completed by intra-operative fusion and updating of the simulation.

We proposed a new FEM based patient specific simulation method to estimate from preoperative data the deformations caused by the introduction of stiff endovascular devices. The approach based on implicit analysis estimates the resulting vasculature deformation without simulating the device insertion process. This approximate solution is consistent with the clinical workflow. In addition, we studied a more elaborate simulation framework. It is based on a more accurate description of mechanical properties of arteries and endovascular devices, and on the simulation of the insertion of multiple endovascular devices via explicit finiteelement analysis. We showed the feasibility of such an explicit numerical scheme. Assuming further developments, it could be used pre-operatively to support decision-making in terms of navigability, access path, endovascular device choice, therapeutic strategy (interventional vs. surgical), aneurism neck behavior, evaluation of new devices ... Additional evaluation and validation is required, especially in cases with complex anatomical configurations.

\section{CONCLUSION}

We developed and implemented an original endovascular navigation system to augment the intra-operative fluoroscopy with the visualization of deformed pre-operative aorto-iliac structure, and related information concerning vessel wall (calcifications), as well as endograft virtual deployment. The proposed solution, that requires only lightweight computer equipment, 
can be integrated into a standard operating room in order to optimize device placement (from a single angle of incidence). Evaluation is currently under way.

\section{ACKNOWLEDGEMENTS}

This work was supported in part by the French national research agency (ANR) through the TecSan program (project ANGIOVISION n ANR-09-TECS-003).

This work has been partially conducted in the experimental platform TherA-Image (Rennes, France) supported by Europe FEDER. 


\section{REFERENCES}

[1] Greenhalgh RM,Powell JT. Endovascular repair of abdominal aortic aneurysm. N Engl J Med, 2008;358(5):452-501.

[2] Becquemin JP, Pillet JC, Lescalie F, Sapoval M, Goueffic Y, Lermusiaux P, et al. A randomized controlled trial of endovascular aneurysm repair versus open surgery for abdominal aortic aneurysms in low- to moderate-risk patients. J. Vasc. Surg. 2011;53:1167-73.

[3] Greenhalgh RM, Brown LC, Powell JT, Thompson SG, Epstein D, Sculpher MJ. Endovascular versus open repair of abdominal aortic aneurysm. N Engl J Med, 2010;362:1863-71.

[4] BecqueminJP, F. Schneider, J.-B. Ricco. Is it Time to Nail the Lid on the Coffin of Open Abdominal Aortic Aneurysm Repair? Not so Sure! European Journal of Vascular and Endovascular Surgery 2012;43:625-626.

[5] Markelj P, Tomazevic D, Likar B, Pernus F. A review of 3D/2D registration methods for image-guided interventions », Medical Image Analysis, 2012;16(3):642-661.

[6] Kaladji A, Lucas A, Kervio G, Haigron P, Cardon A. Sizing for endovascular aneurysm repair: clinical evaluation of a new automated three-dimensional software. Ann Vasc Surg. 2010;24(7):912-20.

[7] Chaikof EL, Fillinger MF, Matsumura JS, Rutherford RB, White GH, Blankensteijn JD, et al. Identifying and grading factors that modify the outcome of endovascular aortic aneurysm repair. J Vasc Surg. 2002;35(5):1061-6.

[8] Dumenil A, Kaladji A, Castro M, Esneault S, Lucas A, Rochette M, Göksu C, Haigron P. Finite elementbased matching of pre- and intra-operative data for image-guided endovascular aneurysm repair. IEEE Transactions on Biomedical Engineering, 2013;in press.

[9] Richens D, Field M, Hashim S, Neale M, Oakley C. A finite element model of blunt traumatic aortic rupture. Eur J Cardiothorac Surg. 2004;25(6):1039-47.

[10] Raghavan ML, Vorp DA, Federle MP, Makaroun MS, Webster MW. Wall stress distribution on threedimensionally reconstructed models of human abdominal aortic aneurysm », Journal of Vascular Surgery, 2000;31(4): 760-769.

[11] Li Z, Kleinstreuer C. Blood flow and structure interactions in a stented abdominal aortic aneurysm model. Medical Engineering \& Physics, 2005;27, (5):369-382.

[12] Holzapfel GA, Sommer G, Regitnig P. Anisotropic mechanical properties of tissue components in human atherosclerotic plaques. J. Biomech. Eng., 2004;126:657-665.

[13] Kaladji A, Dumenil A, Castro M, Cardon A, Becquemin JP, Bou-Saïd B, Lucas A, Haigron P. Prediction of deformations during endovascular aortic aneurysm repair using finite element simulation. Computerized Medical Imaging and Graphics. 2013; accepted for publication.

[14] Gupta A, Sett S, Wolf B. Investigation of interaction between guidewire and native vessel using finite element analysis. Simulia customer conference, 2010.

[15] Burns J. Optimization of Medical Guidewires Through Controllability Matrix. Mechanical Engineering, Drexel University, 2009.

[16] Walraevens, J. et al. Correlation between compression, tensile and tearing tests on healthy and calcified aortic tissues. Med. Eng. Phys. 2008;30:1098-1104.

[17] Sun JS. Lee KH, Lee HP. Comparison of implicit and explicit finite element methods for dynamic problems. Journal of Materials Processing Technology, 2000;105:110-118.

[18] Harewood FJ, McHugh PE. Comparison of the implicit and explicit finite element methods using crystal plasticity. Computational Materials Science, 2007;39:481-494.

[19] Cook RD, Malkus DS, Plesha ME, Witt RJ. Concepts and applications of finite element analysis, 4th edition, New York : John Wiley \& sons, 2002.

[20] Carrell TWG, Modarai B, Brown JRI, Penney GP. Feasibility and limitations of an automated 2D-3D rigid image registration system for complex endovascular aortic procedures. Journal of Endovascular Therapy, 2010;17(4):527-533.

[21] Penney G, Varnavas A, Dastur N, Carrell T. An image-guided surgery system to aid endovascular treatment of complex aortic aneurysms: description and initial clinical experience. Information Processing in Computer-Assisted Interventions, 2011;13-24.

[22] Goksu C, Haigron P, Acosta O, Lucas A. Endovascular navigation based on real/virtual environments cooperation for computer assisted TEAM procedures. Proceedings of SPIE Medical Imaging, San Diego, USA: SPIE, Bellingham, WA, 2004; 257-266.

[23] Goksu G, Haigron P, Zhang H, Soulas T, Le Certen G, Lucas A. 3D intraoperative localization for endovascular navigation guidance. Surgetica'2002, Computer-aided medical interventions: tools and applications, Sauramps Medical, 2002; 323-329. 
[24] Doyle BJ, Callanan A, Walsh MT, Grace PA, McGloughlin TM. A finite element analysis rupture index (FEARI) as an additional tool for abdominal aortic aneurysm rupture prediction. Vasc Dis Prev, 2009; 6:114-121.

[25] Molony D, Kavanagh E, Madhavan P, Walsh MT, McGloughlin TM. A computational study of the magnitude and direction of migration forces in patient-specific abdominal aortic aneurysm stent-grafts. European Journal of Vascular and Endovascular Surgery, 2010;40(3):332-339.

[26] Lenoir J, Cotin S, Duriez C, Neumann P. Interactive physically-based simulation of catheter and guidewire. Computers \& Graphics, 2006;30(3):416-422.

[27] Tang W, Lagadec P, Gould D, Wan TR, Zhai J, How T. A realistic elastic rod model for real-time simulation of minimally invasive vascular interventions. The Visual Computer, 2010;26:1157-1165. 


\section{FIGURES}

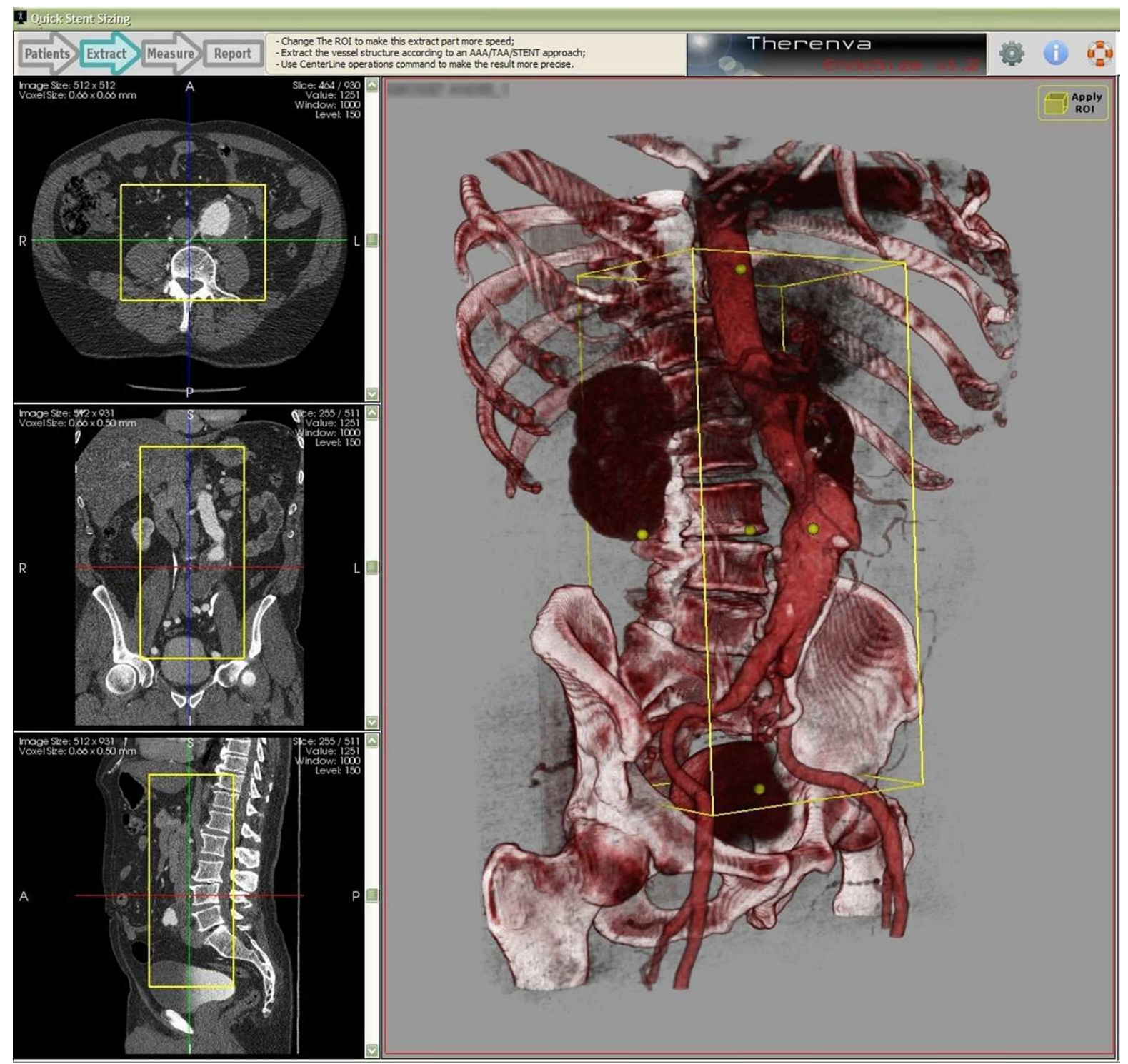

Figure 1: Pre-operative CTA data analysis and description. 


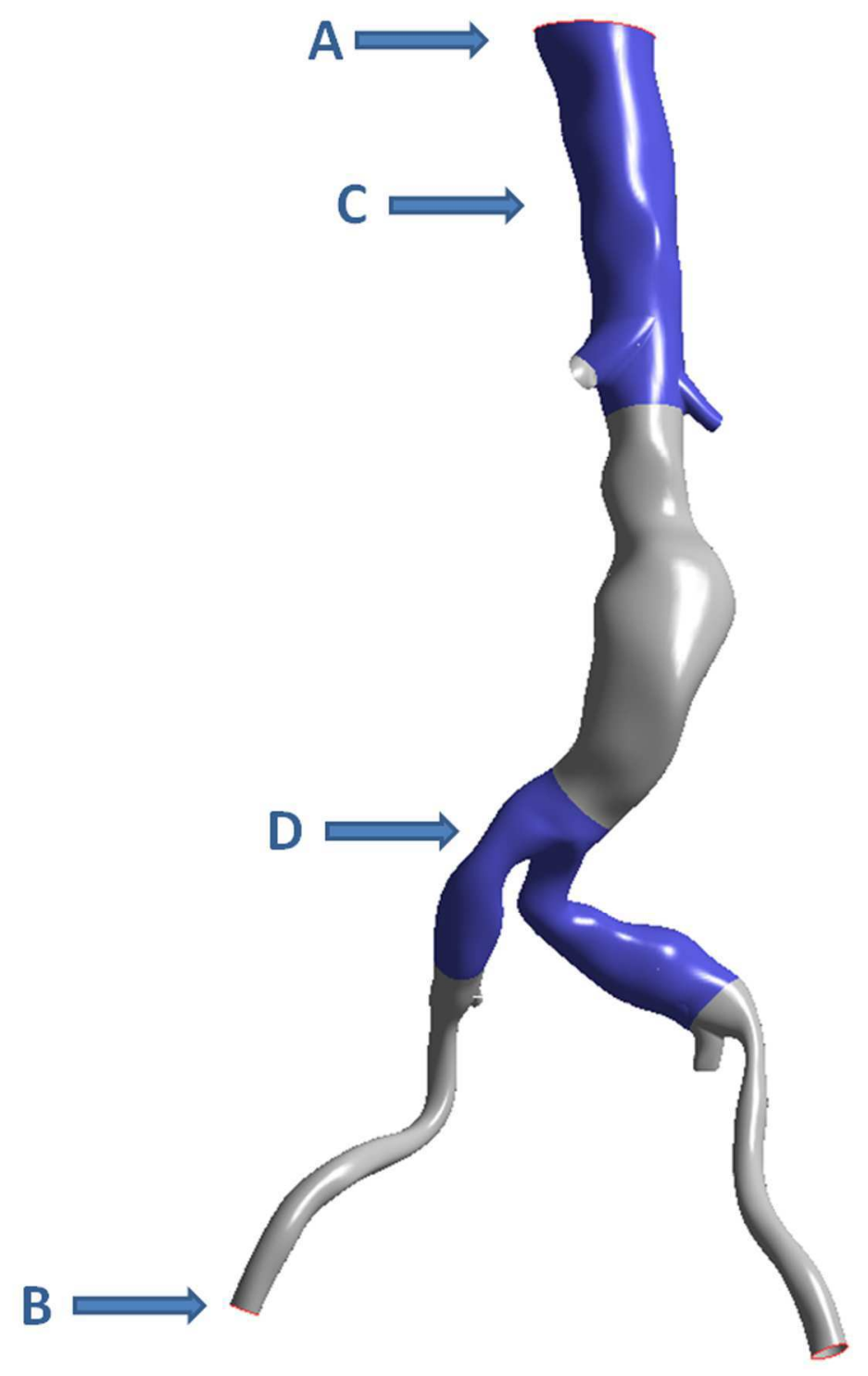

Figure 2: Boundary conditions. 


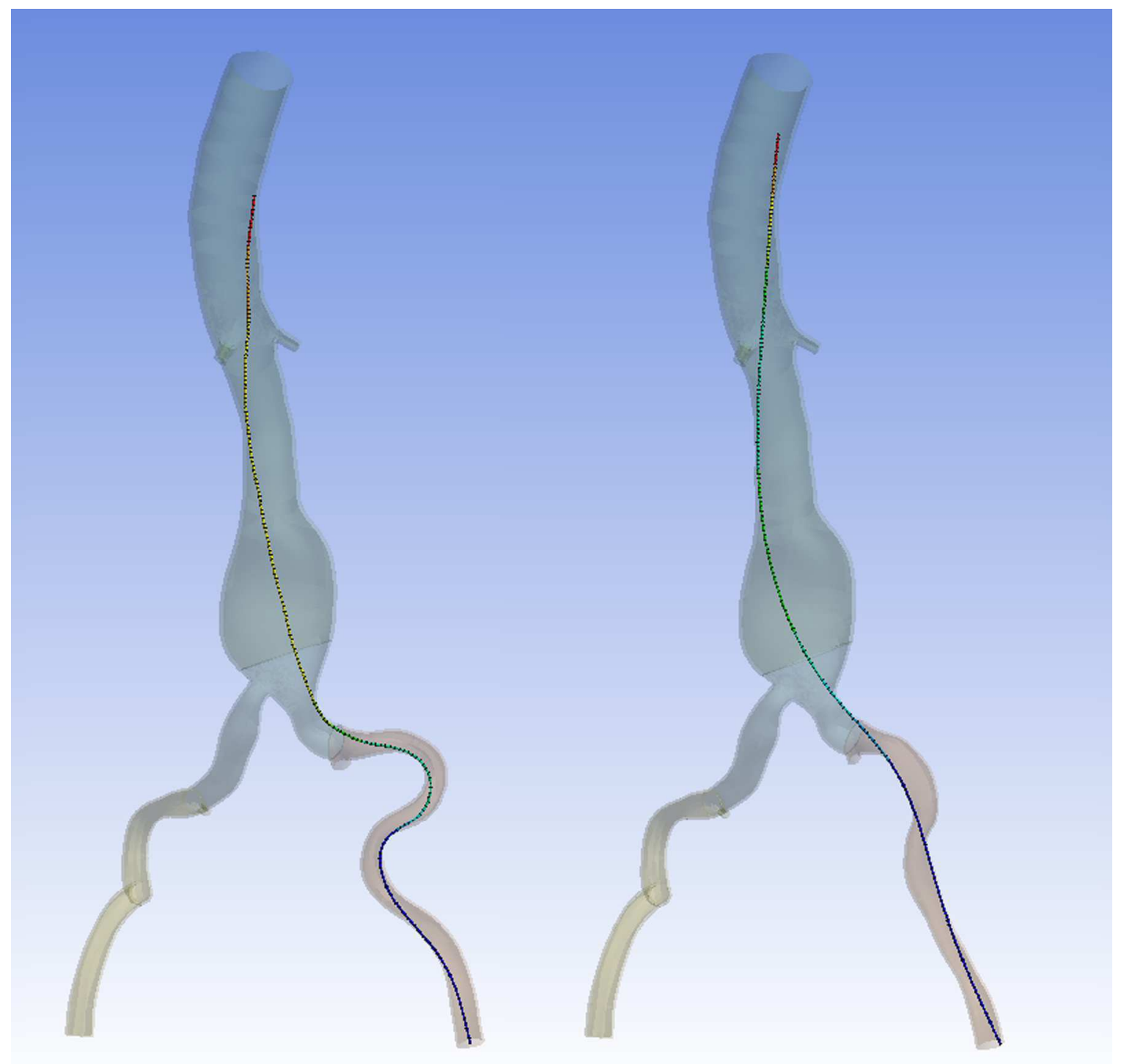

Figure 3: Implicit simulation. 


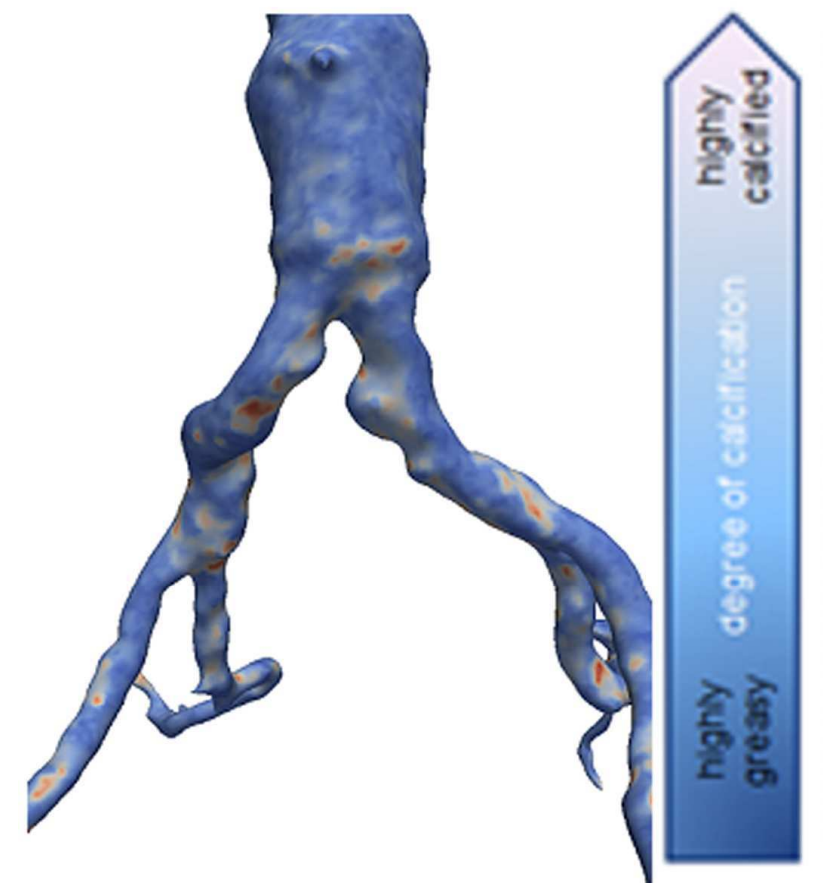

\begin{tabular}{|c|c|c|c|}
\hline Intims & Média & Adventice & $\begin{array}{c}\text { Friction } \\
\text { coeff }\end{array}$ \\
\hline $10.7 \mathrm{MPa}$ & $9 M P a$ & $8.5 \mathrm{MPa}$ & 0.9 \\
\hline $3.4 \mathrm{MPa}$ & $4,1 \mathrm{MPa}_{3}$ & $3.7 \mathrm{MPa}$ & 0.4 \\
\hline $0.7 \mathrm{MPa}$ & $0.4 \mathrm{MPa}$ & $0.16 \mathrm{MPa}$ & 0.1 \\
\hline $0.1 \mathrm{MPa}$ & $0.09 \mathrm{MPa}$ & $0.01 \mathrm{MPa}$ & 0.1 \\
\hline $301 \mathrm{KPa}$ & $505 \mathrm{KPa}$ & $721 \mathrm{KPa}$ & 0.09 \\
\hline $56 \mathrm{KPa}$ & $102 \mathrm{KPa}$ & $162 \mathrm{KPa}$ & 0.05 \\
\hline
\end{tabular}

Figure 4: Mechanical properties of the different layers of the arteries.

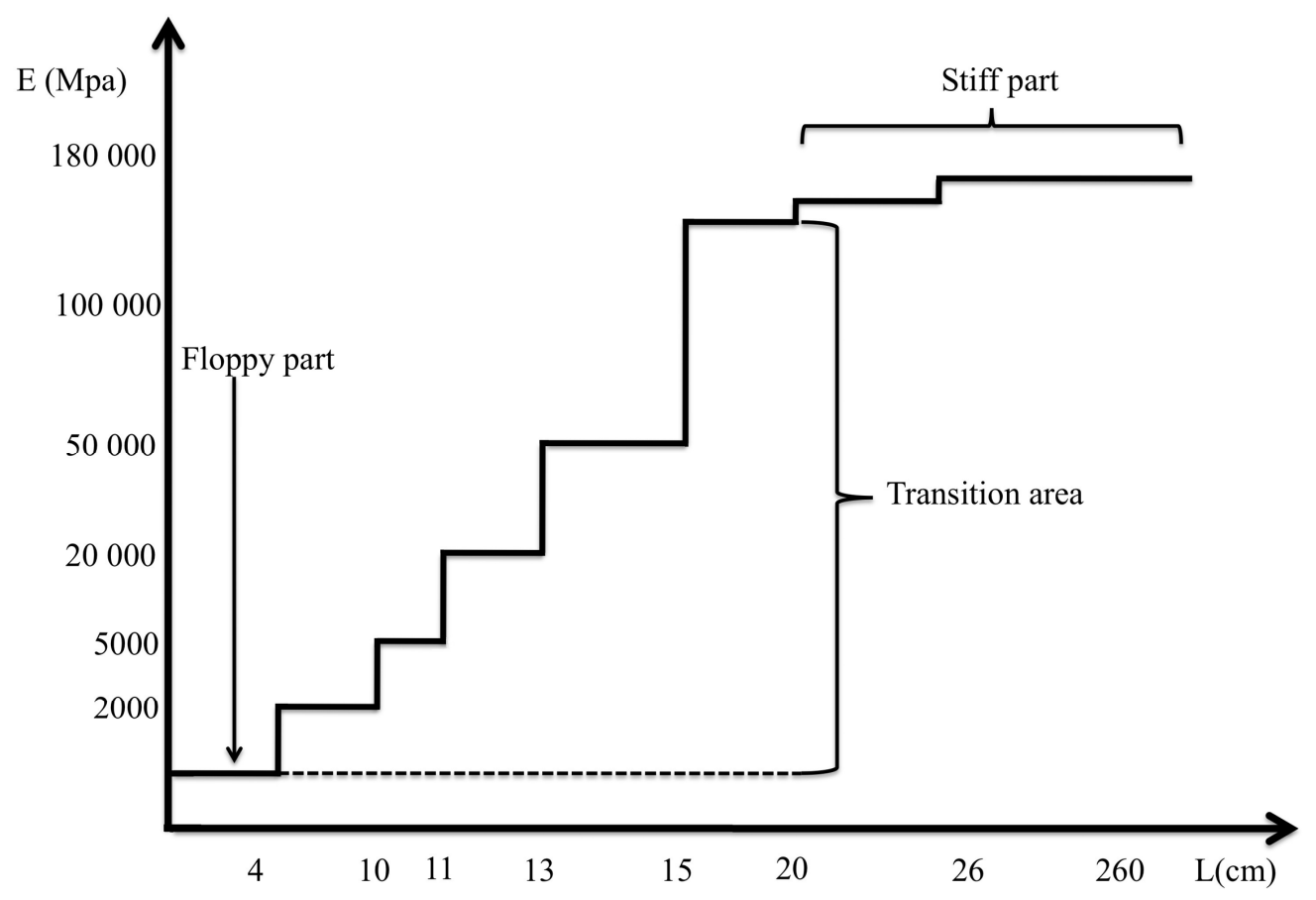

Figure 5: Mechanical testing of endovascular tools. 


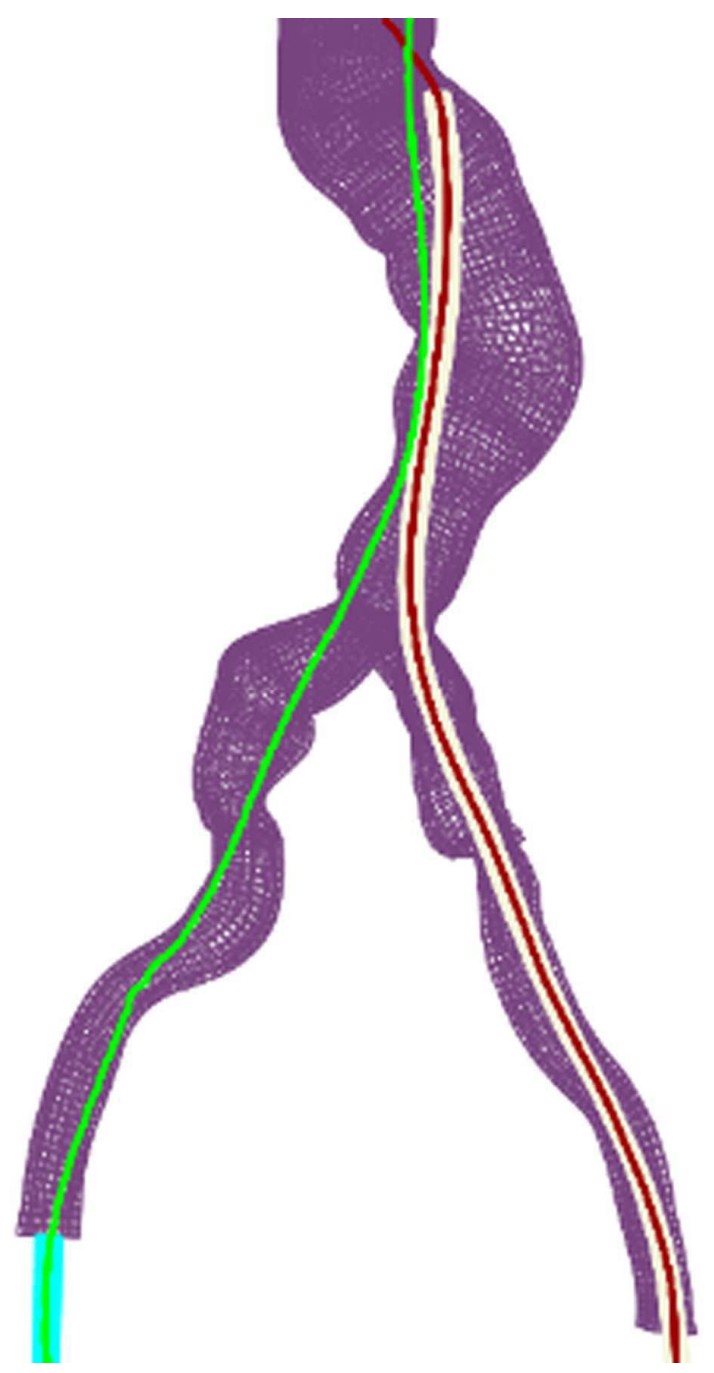

Figure 6: Simulation of the insertion of multiple endovascular devices. 


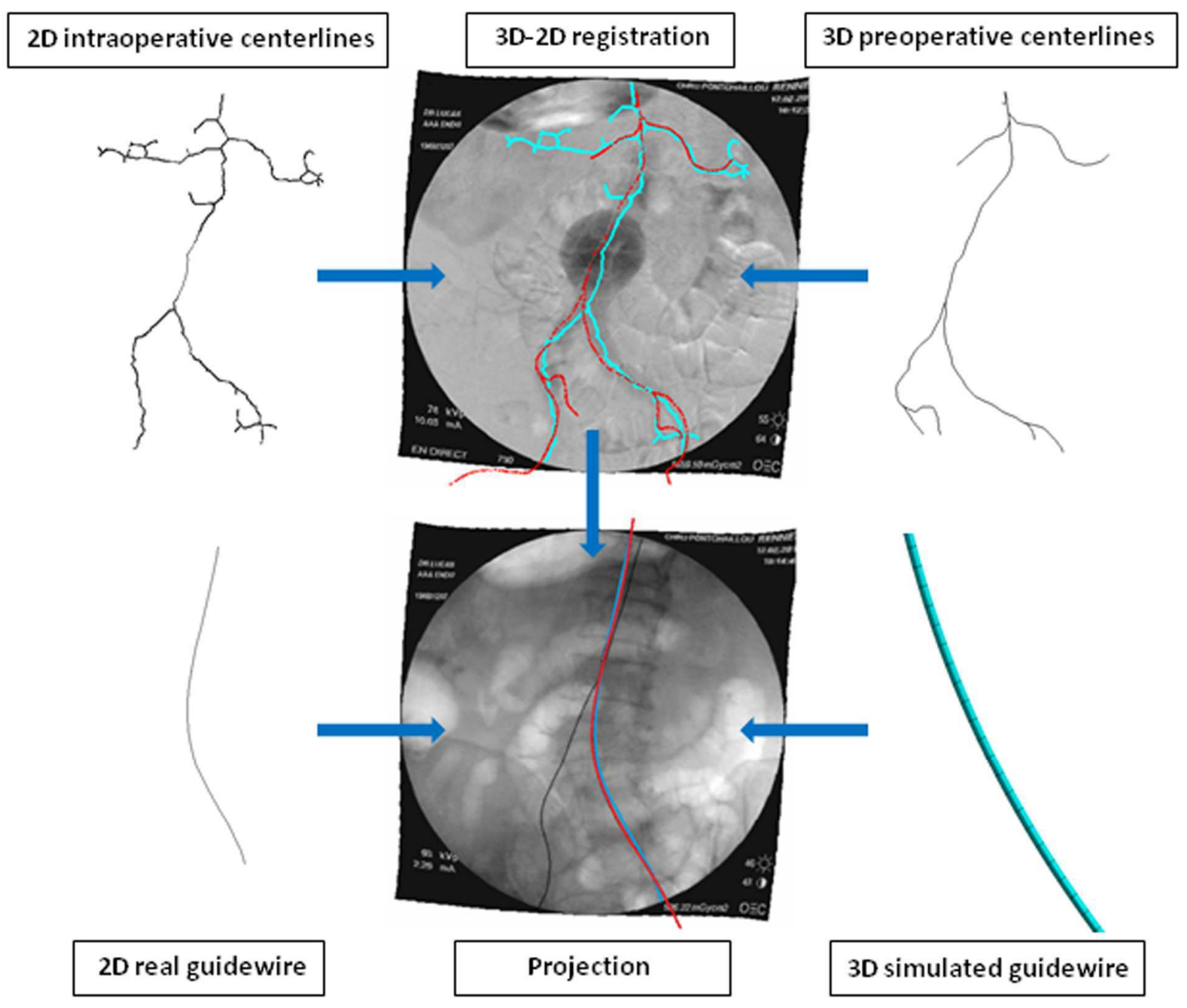

Figure 7: Feature based 3D/2D registration. 

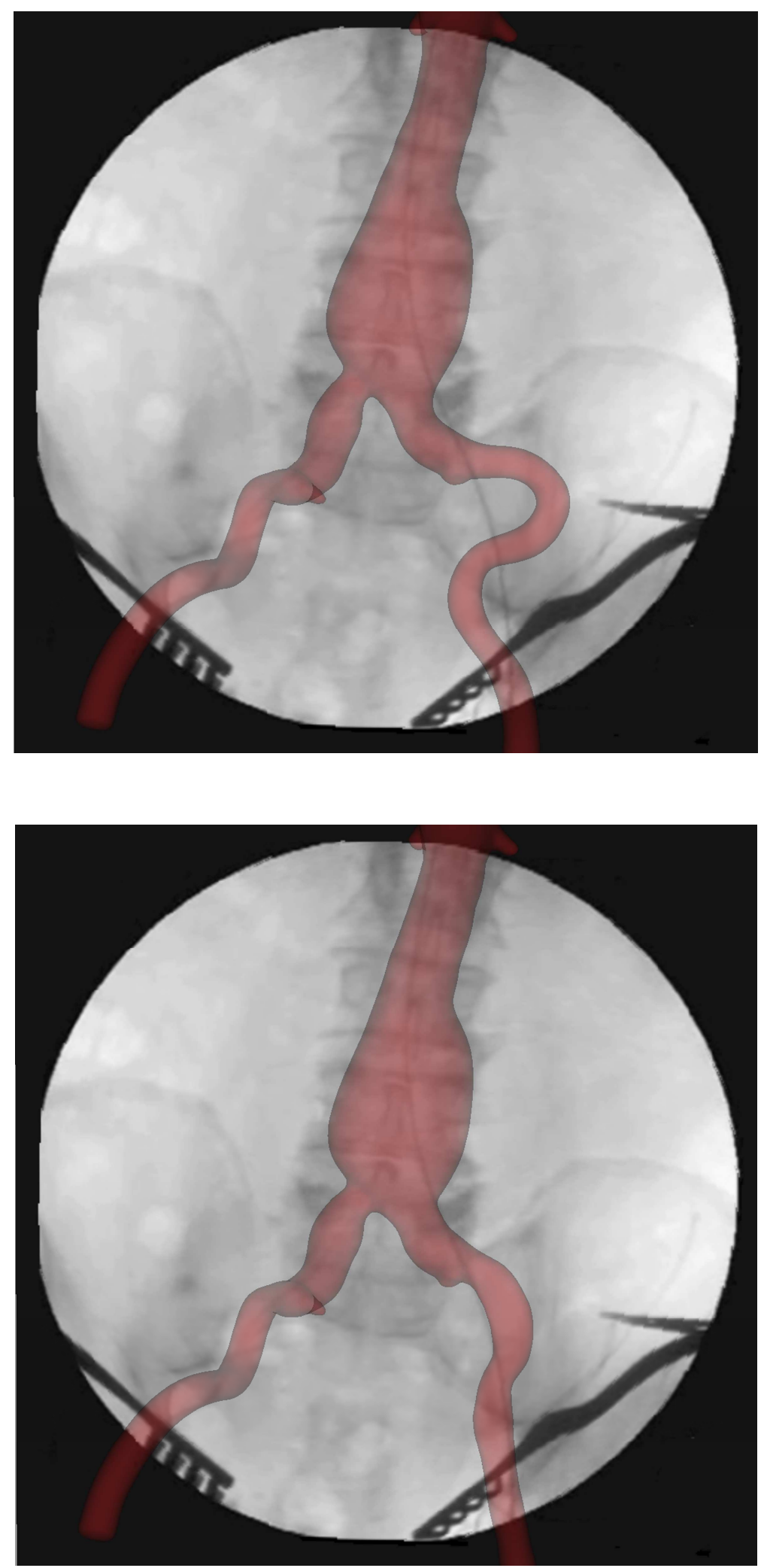

Figure 8: pre- / intra-operative matching. In the roadmap with preoperative aorto-iliac structure (top) the inserted stiff guidewire has deformed the vascular structure. It is not superimposed with the preoperative aorta model. In Roadmap with simulated aorto-iliac structure (down) deformed by the stiff guidewire the observed guidewire is superimposed with the deformed aorta model. 


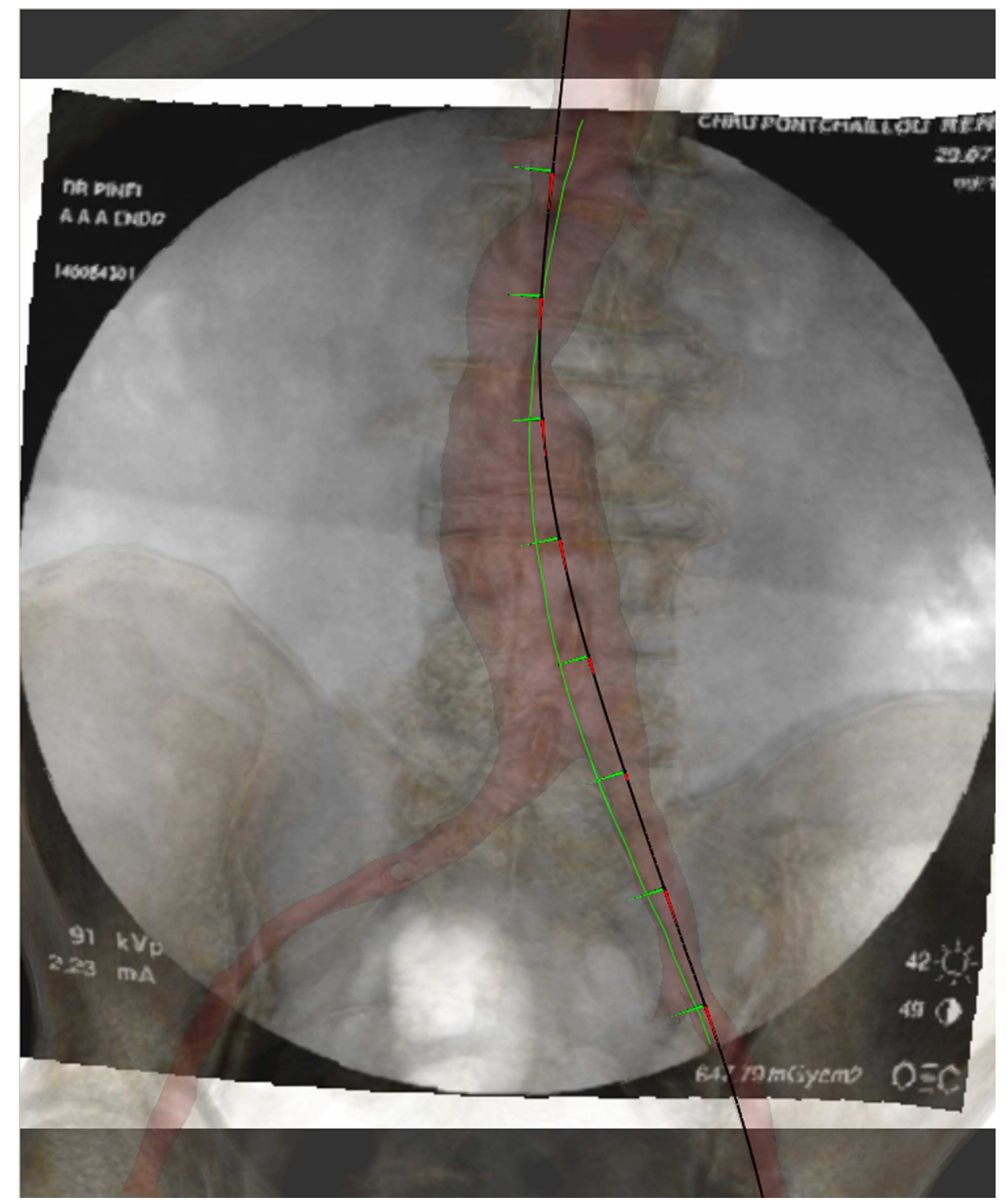

Figure 9: Intra-operative updating of the simulation. 


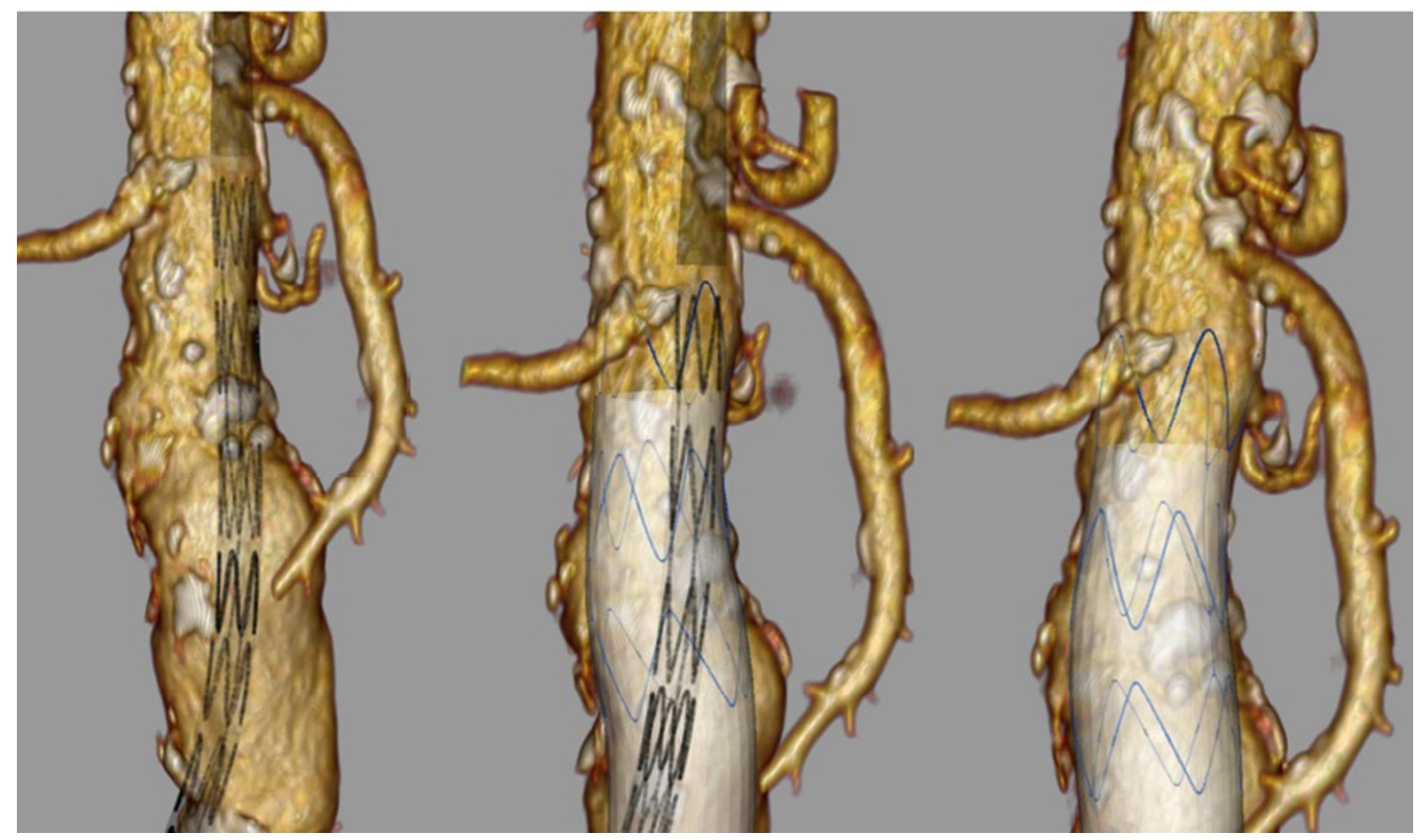

Figure 10: Visualization of stent deployment.
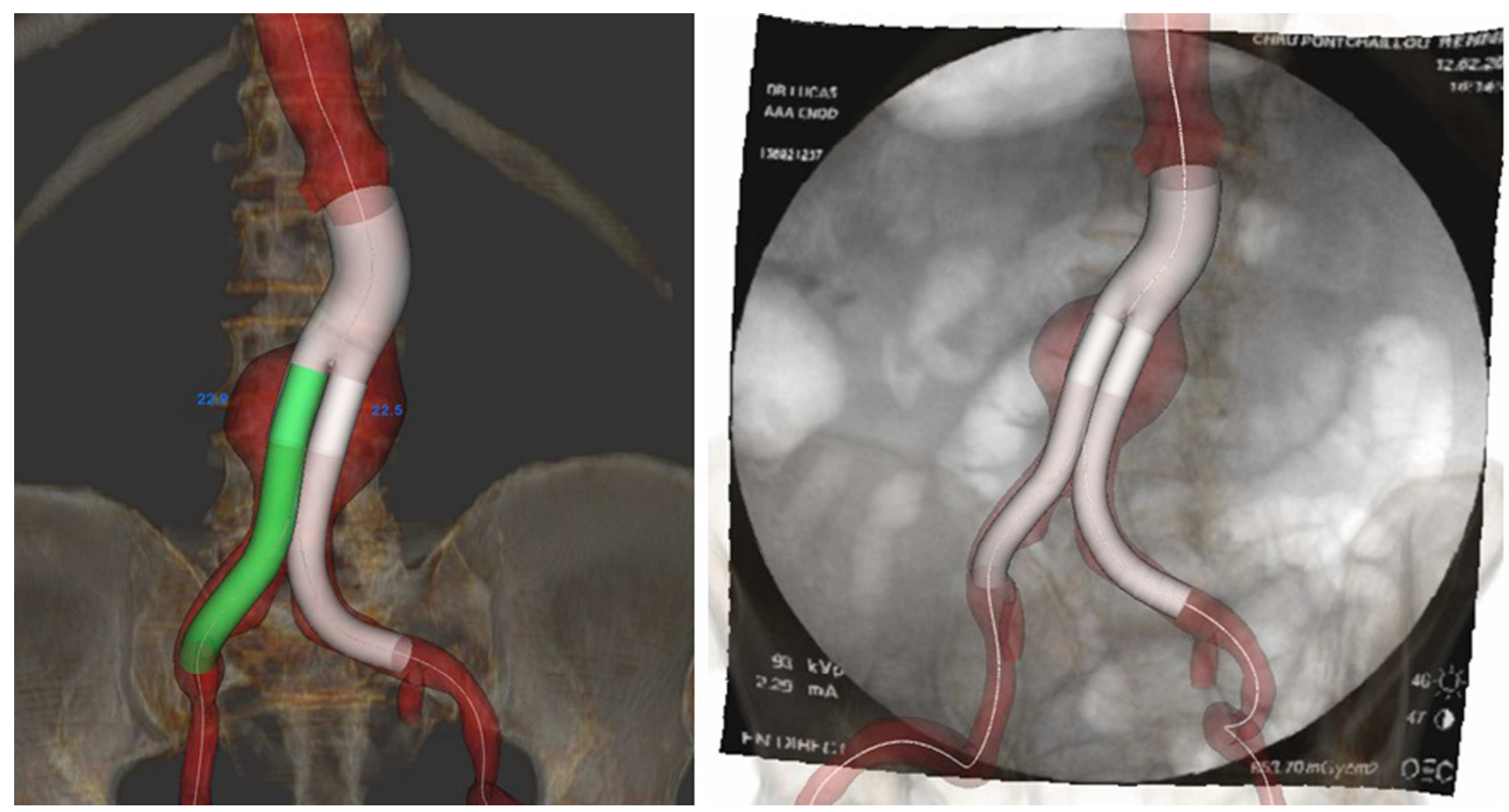

Figure 11: Virtual pre-deployment of the stent graft. 

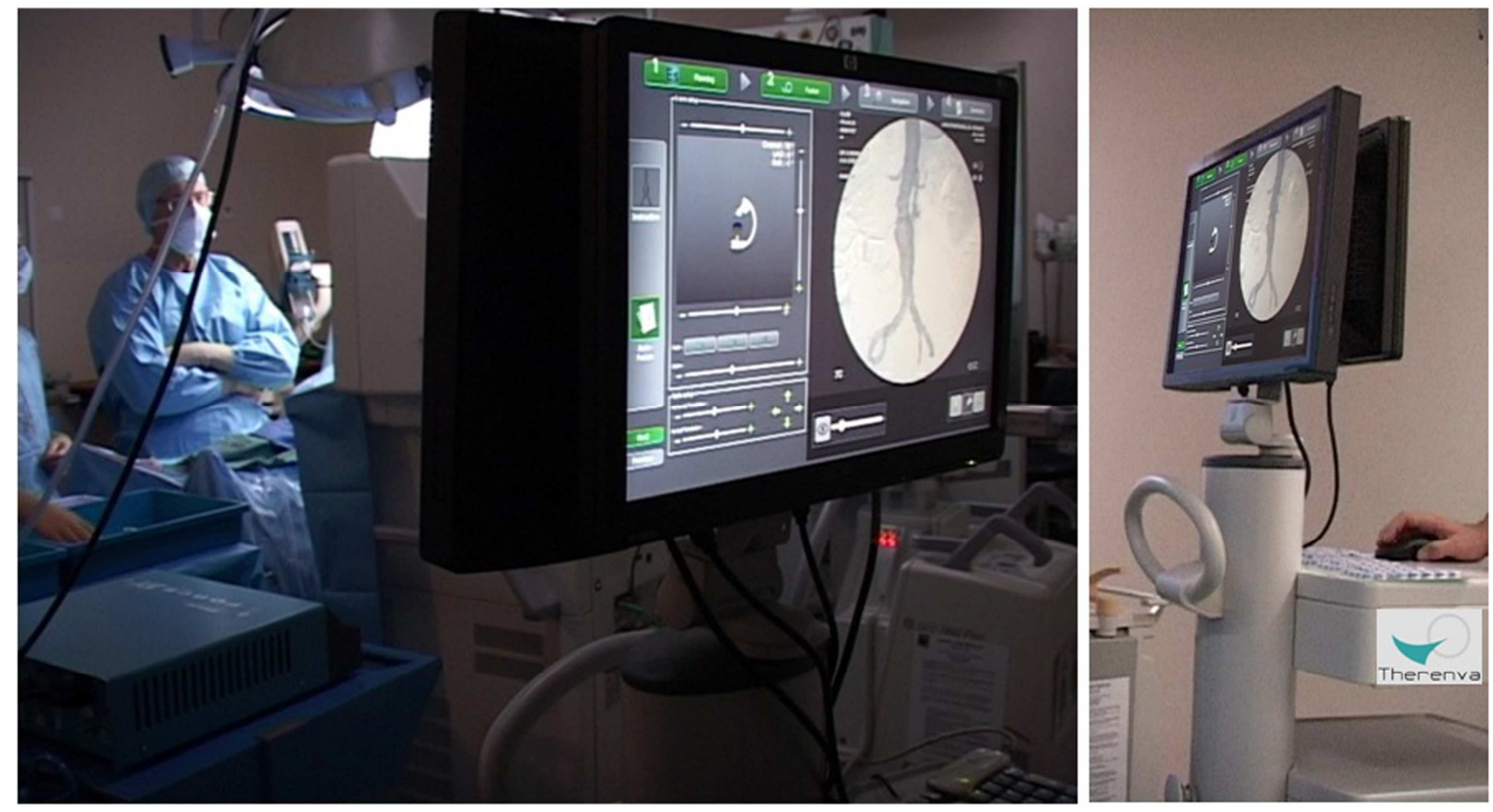

Figure 12: Evaluation of the augmented angionavigation system in the operating room. 